\title{
AFRICANIDADE E AFROBRASILIDADE EM EDUCAÇÃO FÍSICA ESCOLAR
}

\author{
AFRICANNESS AND AFRICAN-BRASILIANNESS IN SCHOOL PHYSICAL \\ EDUCATION
}

AFRICANIDAD Y AFROBRASILIDAD EN EDUCACIÓN FÍSICA ESCOLAR

\author{
Cátia Malaquias Crelier*, Carlos Alberto Figueiredo da Silva*
}

\begin{abstract}
Palavras chave: Educação Física. Racismo. Grupos étnicos.

Resumo: 0 objetivo deste estudo foi examinar as representações de professores e alunos de uma escola localizada no município do Rio de Janeiro sobre relações étnico-raciais e a aplicação da Lei 10.639/03 nas aulas de Educação Física Escolar. Uma pesquisa qualitativa foi realizada, utilizando a observação sistemática, entrevistas semiestruturadas com quatro professores e entrevistas com alunas no grupo focal. O referencial teórico da etnometodologia foi utilizado para examinar os termos indiciais que surgiram nos depoimentos. Constatou-se que metade dos professores entrevistados desconhecia a lei, os termos indiciais indicam que a educação para as relações étnico-raciais não é desenvolvida na disciplina e que o grupo investigado tem consciência desse problema, mas tenta se ocultar nas aparências.
\end{abstract}

Keywords: Physical Education. Racism. Ethnic groups.

Palabras clave: Educación Física. Racismo. Grupos étnicos.

\begin{abstract}
The objective of this study was to examine the representations of teachers and students of a school located in the city of Rio de Janeiro about ethnic-racial relations and the application of Law 10639/03 in Physical Education classes. A qualitative research was conducted using systematic observation, semi-structured interviews with four teachers, and interviews with female students in the focal group. Ethnomethodology was used as a theoretical framework to examine the index terms that emerged in statements. Half the teachers interviewed were unaware of the law; index terms indicate that education for ethnic-racial relations is not developed during the course; and the group investigated is aware of the problem but tries to hide in appearances.
\end{abstract}

Resumen: El objetivo de este estudio fue examinar las representaciones de profesores y alumnos de una escuela ubicada en la ciudad de Río de Janeiro sobre relaciones étnico-raciales y la aplicación de la Ley 10.639/03 en las clases de Educación Física. Una investigación cualitativa fue realizada, utilizando la observación sistemática, entrevistas semiestructuradas con cuatro profesores y entrevistas con alumnas del grupo focal. Se utilizó la referencia teórica de la etnometodología para examinar los términos indiciales que surgieron en los testimonios. Se constató que la mitad de los profesores entrevistados desconocía la ley, los términos indiciales muestran que la educación para las relaciones étnico-raciales no se desarrolla en esa disciplina y que el grupo investigado es consciente de este problema, pero intenta esconderse en las apariencias.
* Universidade Salgado de Oliveira. Rio de Janeiro, RJ, Brasil. E-mail: catiamcrelier@gmail.com; ca.figueiredo@yahoo.com.br

Recebido em: 2/4/2018 Aprovado em: 13/11/2018

DOI: https://doi.org/10.22456/1982-8918.81656 (c) (i) () Licence 


\section{INTRODUÇÃO}

Abordar a questão racial no Brasil não é uma tarefa fácil. Não vivemos a dualidade de outras culturas; a miscigenação nos dá uma sensação de estarmos num paraíso racial. A discussão da temática evoluiu, porém ainda permeada pelo mito da existência de uma convivência amistosa, pacífica e cordial (COELHO; COELHO, 2008).

O Brasil apresenta algumas especificidades nessas reflexões por ter sido um dos últimos países do mundo a abolir a escravização negra/africana (CAVALLEIRO, 2001). Esse processo abolicionista tardio deixou o ex-escravizado e sua descendência entregue à própria sorte. Esses fatos históricos carregam em seu bojo inúmeras consequências negativas que se perpetuam nas representações sociais da sociedade sobre a população afro-brasileira.

Bourdieu e Passeron (1970), em estudo clássico, afirmam que a escola, como um aparelho ideológico de Estado, transmite o saber e a cultura das classes dominantes, e acaba hierarquizando as classes. Neste sentido, o indivíduo afro-brasileiro, inferiorizado historicamente, compõe, majoritariamente, a base da pirâmide social.

Por reconhecer o silêncio e a negação da temática étnico-racial negra em todos os níveis de ensino, a Lei de Diretrizes e Bases da Educação (LDB) foi alterada no ano 2003, tornando obrigatório o ensino sobre história e cultura afro-brasileira.

É notório que a legislação evoca não somente o ensino dos aspectos culturais e históricos, mas propõe uma reflexão profunda das representações da sociedade acerca da população negra na escola, a fim de transformá-la.

O racismo mais tóxico é sutil, velado, internalizado e institucionalizado (ROSSATO; GESSER, 2001). Em estudo realizado sobre as relações e interferências da religião na Educação Física Escolar, quando do desenvolvimento de conteúdos relacionados ao folclore afro-brasileiro, Silva e Silva (2009) verificaram nuances de discriminação nos discursos e nas formas que docentes, pais, responsáveis e discentes lidam com essa questão: "[...] ao entrarem em contato com a diversidade cultural, justificam seu preconceito através de uma fala acordada e ancorada no fundamentalismo religioso de cunho judaico-cristão" (p.566).

Maggie (2006), mapeando as manifestações de racismo e discriminação em 21 escolas de ensino médio do Rio de Janeiro, sinaliza que os alunos e professores não estão preocupados em discutir a questão racial. Para essa autora, a política de cotas divide a sociedade e impõe uma estratificação que não existe nas relações escolares.

Por mais paradoxal que possa parecer, o trabalho de Maggie, apesar de ir de encontro, acaba por reforçar as ideias do racismo na escola. $O$ discurso do mito da democracia racial está presente nas considerações dessa autora. A sutileza do nosso racismo fez e faz com que o imaginário, o vocabulário, as representações, as escolhas, sejam "poluídos" por uma ideologia instituída. A naturalização de ações e falas decorrentes dessa ideologia vai se perpetrando nas relações sociais e se estabelecendo como "verdade".

Estudos como os de Cavalleiro (2001) apontam que desde a educação infantil a criança negra aprende a ser discriminada e a não reagir quando é agredida. Se não houver uma intervenção crítica neste decurso, esta violência se reificará.

Modificar o quadro atual é um processo complexo e paulatino. Mudanças nas representações sociais sobre o racismo no Brasil tendem "[...] a dar-se lentamente e mesmo 
que haja uma grande transformação na representação, ela sempre conserva alguns elementos que pertenciam ao núcleo central anterior, que podem ser reativados" (SILVA, 1998, p.399). Compreendemos, portanto, que a escravização negra no Brasil e a abolição ainda circundam as relações sociais. Embora se tenha evoluído nessas discussões, manifestações racistas são reativadas no ambiente escolar, e também nas aulas de Educação Física Escolar (EFE). Neste sentido, uma implementação não crítica da Lei 10639/03 pode reafirmar concepções equivocadas a respeito da cultura africana e afro-brasileira, realimentando conceitos de cunho negativo, reafirmando os mitos e estigmas, perpetuando preconceitos e falsos paradigmas. Não podemos desconsiderar o fato de sermos produtos de uma educação eurocêntrica e, em virtude disso, nossas metodologias, nossos materiais e nossos conteúdos depreciam tudo aquilo que não é advindo do mundo ocidental (MUNANGA, 2005).

Silva e Devide (2009) apontam ser necessário observar que a construção de ideias preconceituosas se reflete no ambiente escolar, no contexto das aulas de EFE. Tanto a linguagem verbal como a não verbal denunciam a exclusão de um indivíduo ou de um grupo. Este processo denota uma classificação no meio social, hierarquizando e, consequentemente, colocando atores sociais num lugar de superioridade em detrimento de outros.

Alguns estudos que focalizaram as representações de professores de Educação Física sobre este tema têm sido realizados. Pires e Souza (2015) constataram o desconhecimento de professores de Educação Física do município de Bagé em relação à Lei 10639/03, bem como o estranhamento deles quando questionados sobre a cultura afro-brasileira e africana.

Entretanto, há necessidade de verificar as representações de professores de Educação Física em outras localidades brasileiras. Devido a diferenças socioculturais e históricas, o Brasil se apresenta como um lócus gigantesco para estudos sobre relações étnico-raciais, devendo, portanto, receber um tratamento que observe características locais, sem, no entanto, se desprender da dimensão macro.

O presente trabalho tem por objetivo examinar as representações de professores e alunos de uma escola localizada no município do Rio de Janeiro sobre relações étnico-raciais e a aplicação da Lei 10.639/03 nas aulas de Educação Física Escolar.

\section{MÉTODO}

A pesquisa foi realizada em uma instituição de educação básica, situada no bairro de Santa Cruz, na zona oeste do Rio de Janeiro. A cidade do Rio de Janeiro recebeu em torno de 2 milhões de escravos e foi a principal porta de entrada destes indivíduos no Brasil (ELTIS; RICHARDSON 2010). Examinar as relações étnico-raciais nesta cidade contribui efetivamente para ampliar o conhecimento na área de Educação Física Escolar.

O estudo foi realizado em duas fases. A primeira consistiu de entrevistas com quatro professores (dois homens e duas mulheres) de Educação Física. Cabe ressaltar que os quatro professores entrevistados se autodeclararam brancos. Estes professores compõem o quadro total de professores de Educação Física da escola. Como o estudo prende-se à aplicação da Lei 10.639/03, nas aulas de Educação Física Escolar, optou-se por entrevistar apenas os professores de Educação Física.

Na segunda fase, as alunas do oitavo ano do ensino fundamental participaram de uma entrevista no grupo focal. Essas alunas foram reunidas em virtude de, anteriormente, terem 
tido alguma experiência comum e compartilharem opiniões (YIN, 2016). Nesta etapa, tratamos de questões ligadas às relações étnico-raciais que se dão nas aulas. As alunas do oitavo ano foram selecionadas em função de terem sido o grupo observado e por apresentarem mais maturidade para as discussões em relação às turmas dos anos anteriores. Além disso, era a turma com o maior número de meninas da escola.

O estabelecimento destas duas fases foi antecedido por um período de observação de seis aulas, de forma a identificar a pertinência do grupo de alunas à proposta da pesquisa. Em função das interações neste período, o grupo foi então o escolhido para a realização das entrevistas no grupo focal.

Para realizar o grupo focal, lançamos mão daquilo que Banks (2009) denomina como elicitação de opiniões por meio de filme. O filme pode servir como um facilitador no processo de emissão de opiniões e ideias. Assim, exibimos o curta-metragem Vista Minha Pele ${ }^{1}$, para provocar a reflexão dos alunos. 0 filme tem a duração de 24 minutos, o gênero é ficcional educativo; é uma paródia das relações étnicas e sociais no Brasil e baseia-se na convivência escolar. Um dos critérios para a escolha, além do tempo adequado, foi o fato de ter sido criado especificamente para tratar da temática abordada no ambiente escolar.

Para garantir a confiabilidade da pesquisa, realizamos a triangulação desses dados obtidos através desses instrumentos (entrevistas, grupo focal, observação sistemática). Realizamos também a checagem pelos participantes, quando puderam verificar se as interpretações feitas pelas pelos pesquisadores faziam sentido (ALVES-MAZZOTTI, 2002).

A entrevista com o grupo focal foi realizada na sala multimídia da instituição. 0 grupo era composto somente por meninas, haja vista que a instituição oferece a disciplina Educação Física separada em dias e horários diferentes para meninos e meninas. A divisão de gêneros ocorre porque a direção da instituição julga mais adequada por oferecer menos "riscos" para ambos os grupos. Os meninos são entendidos como supostamente mais fortes que as meninas, e têm interesses em atividades distintas.

$\mathrm{O}$ argumento de que os meninos não têm maturidade para estar no mesmo ambiente que as meninas durante a EFE também foi sustentado pela direção, com o argumento de que os alunos estão com os "hormônios aflorados", referindo-se a um suposto apetite sexual, o que poderia trazer riscos à integridade das meninas. 0 vídeo foi exibido na parede da sala projetado no aparelho data show da escola, no laboratório de informática. Todas já estavam cientes de que participavam de uma pesquisa, pois já havíamos conversado sobre essa ação.

Este estudo foi previamente submetido ao conselho de ética da Universidade Salgado de Oliveira. Cada participante assinou o Termo de Consentimento Livre e Esclarecido, tomando ciência do objetivo desta pesquisa, bem como da sua participação voluntária.

\section{DISCUSSÃO E IMPLICAÇÕES}

Para compreender o objeto de estudo, recorremos a alguns conceitos-chave da etnometodologia (COULON, 1997; GUESSER, 2003; SILVA; VOTRE, 2012; SILVA et al., 2015). Buscamos efetivar a análise das entrevistas, interpretando a linguagem dos membros do grupo dentro do contexto social em que interagem. Destacamos alguns dos termos indiciais (expressões, palavras, gestos) que surgiram durante as entrevistas e a observação.

1 Disponível em:<https://www.youtube.com/watch?v=LWBodKwuHCM>. Acesso em: 17 dez. 2018. 


\subsection{Termo indicial 1: "coisas de adolescente"}

O Professor 3 , quando perguntado se já tinha percebido alguma ofensa racista entre os alunos durante a sua aula, nos deu a seguinte resposta: "Ah, já... mas é coisa de adolescente. Eles brigam, mas daqui um pouco estão de bem de novo. Eles se sacaneiam mesmo. Essas coisas que a gente sabe".

Um dos conceitos-chave utilizados na análise é a indicialidade. Herdado da linguística, ele compreende esse caráter transituacional das palavras. Apesar de cada palavra ter 0 seu significado, ela adquire também significados distintos, dependendo do contexto em que é empregada. A incompletude que as palavras e/ou expressões têm só ganha sentido num determinado grupo. A expressão "coisa de adolescente", nesse contexto, vai muito além do seu sentido semântico. Ela nos dá indícios de que certos comportamentos dos discentes são tolerados naquela instituição por causa da faixa etária. São próprios da idade. A fala do docente nos aponta para uma permissividade em algumas práticas. "Falar de indicialidade significa igualmente que o sentido é sempre local e não tem generalização possível" (COULON, 1995, p. 37). Entretanto, tais expressões nos fazem supor que possa haver uma naturalização não somente naquele ambiente. Na sociedade, os adolescentes têm algum tipo de liberdade, concedida pelas leis, pelo imaginário coletivo para ter certas atitudes que não cabem na vida adulta, por ainda estarem num processo de formação.

\subsection{Termo indicial 2: "essas coisas que a gente sabe"}

$\mathrm{Na}$ expressão "essas coisas que a gente sabe", percebemos que existe um código, uma linguagem própria daquele determinado grupo. Quem sabe o que o professor está falando são os membros daquele determinado grupo. Ser membro implica estar filiado ao grupo ou a uma instituição. Só é membro quem tem "incorporado os etnométodos de um grupo social e consegue exibir naturalmente a competência social que o agrega a esse grupo" (COULON, 1995, p. 67). Nós, enquanto pesquisadores, aproximamo-nos da ideia de "essas coisas que a gente sabe", entretanto, muito se oculta nas falas. 0 que depreendemos desta expressão é algo que já está encarnado pelo grupo, sem necessidade de maiores explicações. Reforçam-se aqui os padrões que acabam por se perpetuar, gerando um habitus durável.

\subsection{Termo indicial 3: "coisa e tal"}

Durante as entrevistas percebemos que docentes e discentes lançaram mão de expressões como "essas coisas", "e tal", "coisa e tal" sempre nos finais das frases. Como se houvesse um acordo, um consenso de que nós, pesquisadores, já soubéssemos o não dito. Esse acordo verbal que se faz no meio das interações denomina-se cláusula et cetera. Para Coulon (1995), ao usar expressões como essas, o membro do grupo quer dizer: "Você sabe muito bem o que quero dizer, não preciso insistir, definir com precisão tudo aquilo que se relaciona com aquilo que acabo de dizer, você pode facilmente completar" (p. 35-36).

Essa incompletude é claramente percebida na fala de uma das alunas entrevistadas enquanto versava sobre possíveis situações de discriminação racial no âmbito escolar. 
boa... só zoeira mesmo. Tipo essa parada de cabelo e tal... a galera acha maneiro esse lance de black (Aluna 4).

Práticas racistas e discriminatórias, naquele contexto, "[...] são coisas que a gente sabe, coisas de adolescente, são coisa e tal". Ideias e práticas reificadas, naturalizadas que não se quer superar, pelo fato de não as identificar como problema.

Podemos também pontuar que nós, enquanto pesquisadores, imergimos numa incompreensão semântica quanto à utilização dos vocábulos bullying, racismo e discriminação. Naquele grupo social percebemos que os três termos eram empregados tendo o mesmo significado, apesar de todos estarem dentro de um campo semântico que talvez os agregue em sentidos que os aproximem de agressão, ofensa, a figura do agressor e do agredido. Porém, racismo não é bullying, nem pode ser considerado como "coisas de adolescente". Chamamos a estas dissonâncias de confusão semântica.

Percebe-se que isto a que chamamos de confusão semântica também ocorre entre os alunos. Isso se confirma na fala durante as entrevistas de grupo focal e no cotidiano, como registrado no diário de campo, o que dificulta uma intervenção do corpo técnico num sentido educacional, ou que o ofensor sofra algum tipo de sanção, já que a adolescência, na interpretação do professor, é um momento da vida em que algumas atitudes são aceitáveis e toleráveis.

Identificamos que o professor, entendido aqui como ator social, no decorrer das suas atividades, descreve a sociedade em que vive e ao mesmo tempo a constrói. Práticas discriminatórias são reificadas e naturalizadas pelo professor neste contexto, figura fundamental nos processos de ensinar e aprender. A frase "coisa de adolescente" nos indica que há uma esquiva, uma isenção da escola em interferir em práticas excludentes, porque houve uma convenção social do que é e do que não é aceitável naquele grupo social.

Coulon (1995) nos ajuda a compreender o conceito de reflexividade quando afirma que, enquanto descreve a interação, o ator social está construindo uma realidade, e enquanto ele expressa esta interação está num processo contínuo de compreensão.

Se a questão não é entendida como problema, não há motivos para tentar solucioná-la. Como efeito, e por causa disso, evoluímos lentamente na direção da resolução das tensões nas relações étnico-raciais na nossa sociedade. Apesar da existência de leis que regem a educação formal, é evidente 0 abismo entre 0 que de fato ocorre no cotidiano da escola e 0 que preconiza a legislação.

É inegável que existe uma discussão permanente na sociedade quanto ao que é prerrogativa da família e o que é prerrogativa da escola. Concordamos que ambas são responsáveis pela formação do indivíduo. Esta linha tênue se revela no discurso da Professora 2 quando perguntada se percebe alguma atitude de cunho racista ou discriminatório.

\subsection{Termo indicial 4: "sabe por quê?"}

Ao perguntar à docente sobre as possíveis manifestações de racismo entre os alunos, recebemos a seguinte resposta: 
trabalhamos de forma mais global dentro de um determinado contexto, numa situação específica que aconteça na aula (Professora 2).

Não se trata de isentar a família do importante papel de formar pessoas acolhedoras, inclusivas, com a mente e olhar abertos para a diversidade, mas a escola é, contrariamente à opinião da professora, um terreno propício e não só pode, mas deve incluir estas questões na sua pauta. Ao descrever 0 seu olhar quanto à realidade social construída naquele espaço, 0 ator social nos deixa marcas de como ele presta contas.

Expressões como "sabe por quê?" e "eu penso que" são, neste caso, a materialização da capacidade de descrever e construir a realidade. Esta capacidade chamamos de accountability, pois os atores sociais estão ininterruptamente prestando contas uns aos outros e buscando ajustes na interação (SILVA; VOTRE, 2012).

A questão do papel da família e da escola na formação é bastante ampla e não temos a intenção de trazer soluções peremptórias neste trabalho, mas trazer as contradições e a incompletude da fala do ator social.

A mesma professora, ao ser questionada se julga importante abordar a temática das relações étnico-raciais na Educação Física, nos dá a seguinte resposta: "Penso que os professores exercem importante papel no processo da luta contra o preconceito e a discriminação racial no Brasil e deve sim ser abordado nas aulas de Educação Física (Professora 2)".

O fato de, na segunda pergunta, a professora colocar a Educação Física como um lugar importante para discutir a temática em questão, e num primeiro momento atribuir o dever à família, não é contradição. $O$ ator social formula a sua ideia durante a interação verbal, e isto nos faz pensar que esse ator busca um entendimento a partir do caráter prospectivo e retrospectivo dos acontecimentos. Segundo Silva e Votre (2012, p.28), esse caráter consiste em termos de: "durante as interações verbais aparecerem expressões que antecipem determinadas considerações, ou então comentários passados que subitamente clarificam enunciados presentes". Percebemos claramente as idas e vindas dos discursos no processo de construção da realidade. Sobre os papéis das instituições família e escola na abordagem das questões étnico-raciais, é também uma prerrogativa legal e legítima da escola promover igualdade.

Enquanto estivemos em campo realizando a fase de coleta de dados, observamos algo que atravessou todo o processo e se tornou um fator central nos nossos processos de comunicação: a não fala dos docentes sobre o racismo e a discriminação racial. Tabus são construídos ao longo da nossa história, influenciados e influenciando as nossas representações, como bem retrata Vainfas (1999) ao fazer um resgate historiográfico da miscigenação e da questão racial brasileira. Ideias difundidas, problematizadas ou silenciadas ao longo da historiografia são influenciadoras das nossas relações interpessoais na atualidade.

Falar em racismo no Brasil, principalmente no ambiente escolar e apesar de os espaços de discussão terem se expandido nos meios acadêmicos, ainda é um tabu, uma discussão perigosa que a sociedade evita. Muitos brasileiros acreditam que vivemos em uma democracia racial. Numa sociedade em que negros, brancos, indígenas, asiáticos e outros grupos vivem pacificamente. Creem que os conflitos étnicos e raciais já foram superados, que nossa convivência neste aspecto é harmoniosa. Esta crença inviabiliza todo e qualquer tipo de discussão mais profunda sobre a temática. Neste sentido, Petronilha Silva (2007) elucida 
as dificuldades e desafios da prática de ensinar e aprender em sociedades multiétnicas e pluriculturais. Para tanto, a autora defende que isto irá requerer dos professores:

Não fazer vista grossa para as tensas relações étnico-raciais que 'naturalmente'
integram o dia a dia de homens e mulheres brasileiros; admitir, tomar conhecimento
de que a sociedade brasileira se projeta como branca; ficar atento para não reduzir
a diversidade étnico-racial da população a questões de ordem econômico-social
e cultural; desconstruir a equivocada crença de que vivemos em uma democracia
racial. E, para ter sucesso em tal empreendimento, há que ter presente as tramas
tecidas na história do ocidente que constituíram a sociedade excludente, racista,
discriminatória em que vivemos e que muitos insistem em conservar (SILVA, 2007,
p. 492-493).

Estes são desafios para todos nós, educadoras e educadores do século XXI: tocar em pontos nevrálgicos da sociedade, mexer em assuntos omitidos conscientemente e inconscientemente. Se desejarmos uma escola inclusiva e acolhedora, devemos buscar caminhos para que a multietnicidade e a multiculturalidade sejam aspectos positivos e valorativos na construção do conhecimento. Criar caminhos para que a diversidade seja uma ferramenta para fomentar o respeito. Educar nossos olhos, nosso imaginário, para assim poder influenciar nossos alunos. Rejeitar todo juízo de valor atribuído a determinados grupos, o que gera uma hierarquização e mantém intactas as estruturas de poder.

Um fato a ser ressaltado é que na entrevista de grupo focal havia apenas uma aluna com o fenótipo negro (pele negra, cabelo crespo, nariz negroide). Durante todas as aulas observadas, a aluna se mostrou bastante participativa e comunicativa, com bom desempenho nas aulas de Educação Física e estabeleceu boa relação com as colegas da turma. Durante todo o período da exibição do filme e da entrevista, a aluna não se manifestou. Durante a entrevista, perguntamos se o filme tinha alguma relação com o cotidiano. Recebemos, então, a resposta perturbadora: "Professora, eu não quero falar sobre isso, me faz mal" (Aluna 1).

O Plano Nacional para a Implementação da Lei 10.639/03 (BRASIL, 2003) preconiza que a diversidade étnica deve pautar todo o Projeto Político Pedagógico da escola.

No Ensino Fundamental, 0 ato de educar implica uma estreita relação entre as crianças, adolescentes e os adultos. Esta relação precisa estar pautada em tratamentos igualitários, considerando a singularidade de cada sujeito em suas dimensões culturais, familiares e sociais. Nesse sentido, a educação das relações étnico-raciais deve ser um dos 51 elementos estruturantes do projeto político pedagógico das escolas (BRASIL, 2004, p. 51).

Durante nossas entrevistas, identificamos que dois professores não sabiam sequer do que trata a Lei. Fato semelhante foi constado por Pires e Souza (2015), em estudo já citado. Todos os professores entrevistados se formaram após o ano de 2003, ano da promulgação da Lei. Este dado aponta que a aplicação da Lei 10.639/03 ainda não se efetivou nesta escola, pelo menos na disciplina Educação Física.

Quando perguntamos se em algum momento na formação houve uma discussão a respeito da temática ou alguma disciplina que pudesse abrir espaço para 0 assunto, todos disseram que não. Isto poderia nos apontar uma falha na formação e em decorrência disso todos terem apresentado muita dificuldade em relacionar esta temática ao campo da Educação Física, apesar de julgarem relevante abordá-la. Entretanto, atribuir à formação inicial a responsabilidade talvez não seja o caminho mais adequado, haja vista a possibilidade de formação continuada e de referenciais teóricos disponíveis na literatura. No entanto, isto está 
estreitamente relacionado ao nosso modelo educativo, ainda eurocêntrico e estruturado para satisfazer grupos hegemônicos. É urgente reformularmos métodos, conteúdos, bem como as abordagens utilizadas no nível superior. É o primeiro passo para uma formação voltada para a diversidade cultural.

De acordo com as falas dos professores, o plano de ensino está pautado numa perspectiva desportivizante. Fator comprovado por nós na observação, porém, percebemos que há negligência em relação às dimensões sociais do esporte². 0 esporte, enquanto fenômeno social reflete na sociedade, servindo como ponto de partida e chegada para discutir questões de extrema relevância, como violência, gênero, racismo, discriminações, impunidade.

Os professores não veem na Educação Física, enquanto componente curricular, um espaço propício para abordar esta temática, porque o currículo escolar ainda é pautado na perspectiva dos esportes. $O$ despreparo e a consequente insegurança em abordar a temática são evidentes.

Por que, ao ensinar basquetebol, o professor não aborda o processo de inserção dos negros na liga profissional dos Estados Unidos, apenas em 1950, e como isso impactou a modalidade até os dias atuais, no modo de jogar, nas características dos clubes? Por que não trazer para a pauta como esta luta no campo esportivo se confunde com a luta pelos direitos civis americanos? Por que não incluir a influência do basquete de rua, do hip hop, do rap, do grafite na cultura construída pelos jovens brasileiros?

Por que não falarmos de uma suposta supremacia negra em determinados esportes e a não representatividade em outros? Por que não elencar a não representatividade de pessoas negras em determinados esportes?

Por que não tratarmos da trajetória do negro no futebol carioca e nacional, já que estamos aqui, e como isso impactou e impacta diretamente na maneira de jogar? Por que não falarmos dos recorrentes episódios de racismo e discriminação racial no esporte? Por que não recontar a história de forma positiva?

Vivemos um tempo em que é cada vez mais urgente criar contranarrativas para, quiçá um dia, superarmos estigmas e estereótipos cristalizados no imaginário coletivo em relação aos indivíduos negros. Portanto, ao abordar questões relacionadas ao racismo no/do esporte, é importante que o professor, entendido como um fundamental agente de educação e cidadania, não restrinja esse tema tão amplo aos casos de ofensas que ocorrem nas arenas e estádios. Apesar de ser uma das manifestações, ela é a mais explícita.

Sobre essa temática o professor deve também abordar mais três dilemas que consideramos pontos nevrálgicos nas relações étnico-raciais no esporte: primeiro falar sobre os fatores socioeconômicos que impedem meninas e meninos negros de praticarem determinados esportes, gerando uma falsa ideia de que aquele determinado esporte é para um determinado nicho étnico, como o tênis, a natação, esportes aquáticos, hipismo, entre outros.

Um ponto relevante a ser discutido é a não representatividade dos afro-brasileiros nos cargos de gestão e tomada de decisão no esporte. Este não acesso é multifatorial.

Outro fator impeditivo éa histórica associação desse grupo étnico a atividades laborativas braçais, em que é necessário o uso da força ou habilidade física, como se houvesse uma 
predisposição genética e social para este tipo de trabalho, rechaçando qualquer possibilidade de exercer a cognição, a inteligência e a liderança. Estas estruturas devem ser reeditadas nas nossas mentes, fundamentalmente as mentes dos professores. Essa estrutura social tem a ver com a lógica de lugares.

Quando iniciamos a exibição do filme, a Aluna 2, sem ser perguntada, disparou a seguinte afirmação: "Esse filme é todo trocado, a família branca é pobre e os pretos são ricos, só se for no mundo deles". Prontamente, a Aluna 5 corrobora: "É mesmo, só no mundo deles que é assim. E a mãe é empregada".

Enquanto classificarmos essas falas como reproduções inocentes do panorama social vigente, continuaremos a criar impedimentos para a ascensão social de meninos e meninas negras. 0 mito da democracia racial, ainda tão presente no nosso cotidiano, dificulta a problematização dessas iniquidades e, consequentemente, a criação coletiva de novas visões de mundo, a fim de edificar meninos e meninas negros nas nossas escolas. Esta é a tarefa da Lei 10639/03: recontar as histórias e trazer abordagens das culturas contra-hegemônicas. Romper com estas ideias cristalizadas é a tarefa de uma educação libertadora, haja vista que esta visão reducionista encareça indivíduos brancos e negros dentro de ideais preconcebidos.

A temática das relações étnico-raciais não é uma questão simples de ser abordada. Exige estudo e preparação, caso contrário, acabamos por reproduzir e reforçar práticas. Como vemos na fala da Professora 2 ao ser perguntada sobre as relações entre a temática racial e a Educação Física: "Não diretamente, porém abordamos de forma interdisciplinar. Tipo, uma mostra cultural, a Educação Física fica responsável por criar uma dança ou um teatro com expressividade corporal relacionado ao tema" (Professora 2).

Mais uma vez percebemos que não há uma estreita relação entre a cultura africana e afro-brasileira às manifestações artísticas e culturais, e a sua aplicação se dá de forma pontual, estanque. Ou seja, o conceito de cultura neste mote está restrito a manifestações artísticas. A proposta da Lei é que a cultura no sentido mais amplo seja abordada como modos de vida e produção de conhecimento. Por isso, é necessário que a formação continuada desses professores aconteça nesse sentido.

Uma das maiores dificuldades em convocar as pessoas não negras para a discussão da temática das relações étnico-raciais é o fato de não reconhecerem seus privilégios e sua participação na manutenção das estruturas sociais vigentes. Investir nos jovens e adolescentes em idade escolar nos parece uma alternativa eficiente, pois a democratização das redes sociais e o acesso em massa à internet têm trazido à tona discussões e ampliado as visões. Percebemos este fenômeno na fala da aluna ao discorrer sobre seu lugar de privilégio:

\footnotetext{
Ah, mais ou menos. Tipo, se for pensar nessa parada do cabelo dela, ninguém me zoa porque meu cabelo é liso. As pessoas até me perguntam se eu faço alguma coisa para ele ficar assim. Onde eu chego, as pessoas elogiam o meu cabelo. Mas eu vejo as pessoas zoando quem tem cabelo ruim (Aluna 2).
}

A aluna entende que ter um cabelo que se enquadra nos padrões estéticos de beleza estabelecidos como o padrão livra-a de vivenciar situações vexatórias. Reconhecer esses lugares sociais já é um grande avanço e abre portas para outras discussões pertinentes.

Quanto ao uso frequente de expressões racistas e discriminatórias, como "cabelo ruim" ou "cabelo duro", percebemos que são utilizadas sem a pretensão de serem racistas, pois 
há um pensamento coletivo de que não é moral, nem correto sê-lo. Tais expressões estão incorporadas no vocabulário e uma das tarefas da Lei é identificá-las para desconstruí-las.

O corpo em movimento traduz e expressa sensações, sentimentos, conta histórias, ama e odeia, acolhe e rechaça, envolve-se e distancia-se, diz e cala-se. Na escola e, principalmente, na Educação Física, onde esses fenômenos se consolidam e também se deslocam, é tempo de desconstrução social. Para Kunz (2000, p. 78), "[...] ninguém pode isolar o movimento dos objetos ou do ser que se-movimenta".

As relações étnico-raciais têm sido encaradas no Brasil como um dos grandes desafios a ser enfrentado por nossa sociedade. Pesquisadores, educadores, mídia, legisladores, formadores de opinião, entre outros, têm se dedicado a projetos, debates, discussões, eventos, congressos, de forma a ampliar a visão de todos em relação a esta questão.

A análise dos dados deste estudo demonstra que o caminho a ser percorrido é longo e ainda turbulento. Não há que denunciar mais nada, a denúncia faz parte de outra época. $A$ sociedade tem consciência deste problema, mas é uma consciência que tenta se ocultar nas aparências.

O aparente está reificado. Mas, ocultas no aparente, estão as marcas do racismo. Elas se escondem nas metáforas, nas "brincadeiras", nas metonímias, no dia a dia, na informalidade.

O espaço para a reflexão necessita ser ampliado. As legislações têm um papel importante para gerar a mudança, mas isto precisa ser "encarnado" e não apenas "internalizado". É preciso que sintamos na pele, que incorporemos ao nosso corpo as ações necessárias para a mudança. Internalizar as legislações não é suficiente, precisamos vivenciá-las, fazer uso delas, colocá-las em prática. São as ações práticas que importam. O que de fato ocorre quando inventamos o cotidiano? Por que não construir um mundo social livre do racismo? 0 que nos impede?

Talvez estas questões possam nos fazer seguir adiante.

\section{REFERÊNCIAS}

ALVES-MAZZOTTI, Alda Judith. O planejamento de pesquisa qualitativa. In: ALVES-MAZZOTTI, Alda Judith; GEWANDSZNAJDER, Fernando (Org.). 0 método nas ciências naturais e sociais: pesquisa quantitativa e qualitativa. 2. ed. São Paulo: Thompson, 2002. p. 147-178.

BANKS, Marcos. Dados visuais para pesquisa qualitativa. Porto Alegre: Artmed, 2009.

BOURDIEU, Pierre; PASSERON, Jean-Claude. La reproduction. Eléments pour une théorie du système d'enseignement. Paris: Editions de Minuit, 1970.

BRASIL. Lei n. 10.639, de 9 de janeiro de 2003. Altera a Lei no 9.394, de 20 de dezembro de 1996, que estabelece as diretrizes e bases da educação nacional, para incluir no currículo oficial da Rede de Ensino a obrigatoriedade da temática "História e Cultura Afro-Brasileira", e dá outras providências. Diário Oficial da União, Brasília, DF, 10 jan. 2003, p. 01. Disponível em: <http:// www.planalto.gov.br/ccivil_03/Leis/2003/L10.639.htm>. Acesso em: 17 dez. 2018. 
BRASIL. Conselho Nacional de Educação. Parecer n‥ 03 de 10 de março de 2004. Dispõe sobre as diretrizes curriculares nacionais para a educação das relações étnico-raciais e para o ensino de história e cultura afrobrasileira e africana. Relatora: Petronilha Beatriz Gonçalves e Silva. Ministério da Educação. Brasília, julho de 2004. Disponível em: <http://portal.mec.gov.br/ cne/arquivos/pdf/003.pdf>. Acesso em: 17 dez. 2018.

CAVALLEIRO, Eliane. Educação anti-racista: compromisso indispensável para um mundo melhor. In: CAVALLEIRO, Eliane (org.). Racismo e anti-racismo na educação: repensando nossa escola. São Paulo: Selo Negro, 2001.

COELHO, Wilma de Nazaré Baía; COELHO, Cezar (Orgs). Raça, cor e diferença: A escola e a diversidade. Belo Horizonte: Mazza, 2008.

COULON, Alain. Etnometodologia. Petrópolis. Vozes, 1995.

ELTIS, David; RICHARDSON, David. Atlas of the transatlantic slave trade. New Haven; Londres: Yale University, 2010. Disponível em: <http://slavevoyages.org >. Acesso em: 10 out. 2018.

GUESSER, Adalto. A etnometodologia e a análise da conversação e da fala. Revista Em Tese, v. 1, n. 1 (1), ago. p. 149-168, 2003. DOI: https://doi.org/10.5007/\%25x. Disponível em: <https:// periodicos.ufsc.br/index.php/emtese/article/view/13686>. Acesso em: 17 dez. 2018.

KUNZ, Elenor. Transformação didático-pedagógica do esporte. ljuí: Editora Unijuí, 2000.

MAGGIE, Yvonne. Racismo e anti-racismo: preconceito, discriminação e os jovens estudantes nas escolas cariocas. Educação e Sociedade, v.27, n.96, p.739-751, 2006. DOI: http://dx.doi. org/10.1590/S0101-73302006000300006. Disponível em: <http://dx.doi.org/10.1590/S010173302006000300006>. Acesso em: 17 dez. 2018.

MUNANGA, Kabengele. Nosso racismo é um crime perfeito. [Entrevista concedida a] Camila Souza Ramos e Glauco Faria. Revista Fórum, 9 dez. 2012. Disponível em: <https://www. revistaforum.com.br/nosso-racismo-e-um-crime-perfeito/>. Acesso em: 17 dez. 2018.

PIRES, Joice Vigil Lopes Pires; SOUZA, Maristela da Silva. Educação Física e a aplicação da lei no 10.639/03: análise da legalidade do ensino da cultura afro-brasileira e africana em uma escola municipal do RS. Movimento, v. 21, n. 1, p. 193-204, jan./mar. de 2015.

ROSSATO, Cesar; GESSER, Verônica. A experiência da branquitude diante de conflitos raciais: Estudos de realidades brasileiras e estadunidenses. In: CAVALLEIRO, Eliane.

Racismo e anti-racismo na educação: repensando a nossa escola. São Paulo: Selo Negro, 2001.

SILVA, Carlos Alberto Figueiredo da. A linguagem racista no futebol brasileiro. In: CONGRESSO BRASILEIRO DE HISTÓRIA DO ESPORTE, LAZER E EDUCAÇÃO FÍSICA, 6, 1998. Rio de Janeiro.

Anais.... Rio de Janeiro: Universidade Gama Filho, 1998, p. 394-406.

SILVA, Carlos Alberto Figueiredo da; DEVIDE, Fabiano Pries. Linguagem discriminatória e Etnométodos de exclusão nas aulas de educação física escolar. Revista Brasileira de Ciências do Esporte, v. 30, n. 2, p. 181-197, jan. 2009.

SILVA, Carlos Alberto Figueiredo da; VOTRE, Sebastião Josué (Orgs.). Etnometodologias. Rio de Janeiro: HP Comunicação, 2012. 
SILVA, Carlos Alberto Figueiredo da et al. A contribuição da etnometodologia para os estudos sociológicos na Educação Física brasileira. Movimento, v. 21, n. 1, p. 233-248, jan./mar. de 2015.

SILVA, José Edmilson da; SILVA, Carlos Alberto Figueiredo da. Educação física, folclore e religião: relações e interferências. Revista da Educação Física/UEM, v. 20, n. 4, p. 555-567, 2009. DOI: $10.4025 /$ reveducfis.v20i4.6323. Disponível em: <http://www.periodicos.uem.br/ojs/index. php/RevEducFis/article/view/6323>. Acesso em: 17 dez. 2018.

SILVA, Petronilha Beatriz Gonçalves. Aprender, ensinar e relações étnico-raciais no Brasil. Educação, v. 63, n. 3, p. 489-506, set./dez. 2007.

VAINFAS, Ronaldo. Colonização, miscigenação e questão racial: notas sobre equívocos e tabus da historiografia brasileira. Tempo, n.8, p.1-12, 1999.

YIN, Robert. Pesquisa qualitativa do início ao fim. Porto Alegre: Penso, 2016. 
